\title{
Exploring Bahraini Parents' Views on Parental Involvement in Primary Education
}

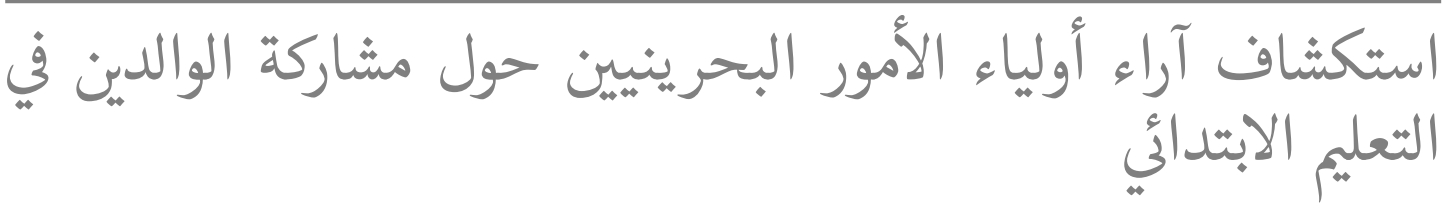

\section{Osama Al-Mahdi*, Lucy Bailey}

Bahrain Teachers College, University of Bahrain, Sakhir, Kingdom of Bahrain

Corresponding Author: Osama Al-Mahdi;

email: oalmahdi@uob.edu.bh

\section{ORCID}

Osama Al-Mahdi: https://orcid.org/0000-0002-6997-0430

Lucy Bailey: https://orcid.org/0000-0003-1828-6273

\section{Submitted: Feb. 27, 2021}

Accepted: September 30, 2021

Published: January 31, 2022

Production and Hosting by Knowledge E

(c) Osama Al-Mahdi, Lucy Bailey. This article is

distributed under the terms of the Creative Commons

Attribution License, which permits unrestricted use and redistribution provided that the original author and source are credited.

Managing Editor:

Natasha Mansur

\section{Abstract}

This article reports on an exploratory study of parental involvement in primary education conducted in the Kingdom of Bahrain. Drawing on a survey of 154 parents across 16 schools, parent views on parental involvement are explored - specifically, beliefs and experiences about parental involvement, and who should be held responsible for ensuring parental involvement. The study finds that the participants viewed all types of parental involvement identified by Epstein (2011) as important, and that it was emphasized by their children's schools, but had a school-centered view of home-school relations. Furthermore, they identified a range of barriers to parental involvement, with parents' other responsibilities featuring as the most important. Cultural factors influencing parental involvement within the specific cultural context of Bahrain are discussed.

المالخصن

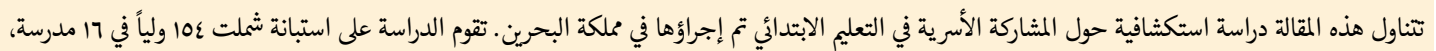

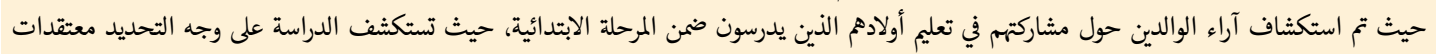

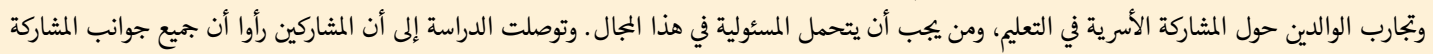

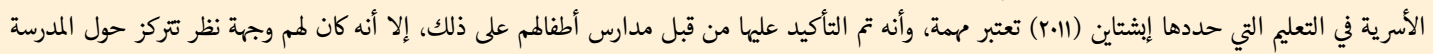

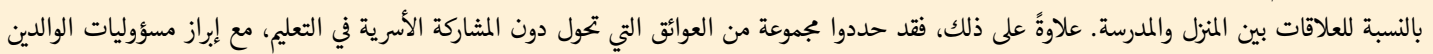

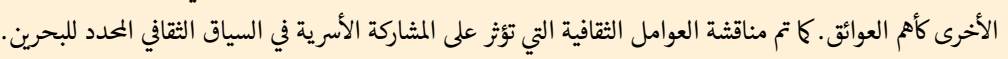

Keywords: Education, Parental involvement, Parental engagement, Bahrain, Primary education

$$
\text { الكالمات المفتاحية: التعليم، المشاركة الأسرية، مشاركة الوالدين، البحرين، التعليم الابتدائي }
$$




\section{Introduction}

A wealth of evidence documents the positive outcomes associated with parental involvement in education (Daniel, 2011; Desforges \& Abouchaar, 2003; Goodall \& Montgomery, 2014). These benefits include better school achievement, better attendance, and improvements in attitude and behavior (Al Taneiji, 2013). An extensive body of literature also charts the importance of culture to the ways in which parent-school partnerships can best be fostered (LaRocque, et al., 2011). Yet, there is insufficient research into this topic in the cultural context of the Gulf States, and a dearth from the Kingdom of Bahrain. This article begins to address this significant gap in the existing research.

There is a growing awareness within Bahrain about the need to promote strong relationships between school and families, which is now one of the strategic goals of the Ministry of Education. In addition, the Bahrain Education and Training Quality Authority (BQA), which inspects all schools in the Kingdom, considers these strong relationships as an indicator of school success in creating positive learning environment (Bahrain Education and Training Quality Authority, 2015). It is of direct utility to educational policymakers and practitioners in Bahrain to understand any impediments to creating such barriers.

Although there is a wealth of research investigating parental involvement in Western contexts, the cultural and educational context of Bahrain (and the Gulf states more broadly) means that we cannot expect the forms of, and barriers to, involvement in Western contexts to be applicable here. The existing literature is predominantly Western-centric; hence, this article draws on data collected from Bahraini parents in order to explore how parental involvement is conceptualized in the Bahraini context, and to explore the continuities and contrasts with international literature on parental involvement. The research explores parent perspectives concerning parental involvement in public primary schools in Bahrain. We look at the value accorded to parental involvement, experiences of parental involvement, and who is accorded responsibility for parental involvement. We consider the role of aspects of Bahraini culture in this involvement. This article draws from a larger project which investigates parental involvement practices from the perspectives of different stakeholders. 


\subsection{Background: Bahrain}

The Kingdom of Bahrain is an archipelago nation lying in the Arabian Gulf, close to the coast of Saudi Arabia. Its position led to its development as a trading nation; however, it was the discovery of oil in 1932 which brought wealth to Bahrain as well as to the rest of the Gulf region (Karolak, 2010). More recently, there is rising concern that the economy needs to diversify away from both oil and the large public sector, and more attention should be paid to the human capital needed to achieve that. Bahrain was the first Gulf country to develop a public education system in 1919. The first girls' school opened within a decade of the first boys' school. All public schools in Bahrain are segregated by gender. Primary boys' schools are administrated either by male or female staff while girls' schools are administrated only by female staff. Bahrain has a reputation as a moderate and progressive country within the region.

As majority Muslim, Arab, and Arabic speaking countries, the Gulf countries share a common language, culture, and religion. In addition, they face the current challenge of moving away from oil-based economies. The common culture and economic challenges across these nations suggest that research insights from one may be applicable to others in the region.

\section{Literature Review}

This section establishes dimensions of parental involvement in Western contexts, the limited literature that has explored the applicability of this framework in the Gulf Region, and a specific empirical lacuna from the Kingdom of Bahrain. The literature review will begin by examining the concept of parental involvement in education and establishing the parameters to debates regarding parental involvement that have been established in Western research. We then explore how empirical studies have applied this framework, arguing that the linguistically and culturally diverse context of many Gulf states means that findings from the West cannot be simplistically applied here (Moussa-Inaty \& De La Vega, 2013). Having established this background, we move to discussion of research into parental involvement that has been conducted in the Gulf region. Finally, we focus on the very limited literature that exists concerning parents and education in the specific context of the Kingdom of Bahrain. We consider the influence of cultural factors, such as educational practices in relation to gender or views about the role of the family, on parental involvement in this context. 


\subsection{Conceptualizing parental involvement}

An extensive international literature exists on conceptualizing parental involvement in their children's education. This literature examines different types of parental involvement; responsibility for ensuring parental involvement; and the barriers to effective parental involvement. Although some commentators have argued for the use of different terms, such as "parental engagement" to emphasize that the focus should be on parents' engagement with children's learning rather than their involvement with school (Goodall \& Montgomery, 2014), we employ the term that has been most consistently used in the literature in the Gulf region (Al-Mahrooqi et al., 2016; Al Harrasi \& Al-Mahrooqi, 2014). Parental involvement refers to the broad range of activities that engage parents and children in learning activities at home and at school. There are many ways that parents can become involved in their children's education, and attempts have been made to categorize such involvement. The most widely adopted framework is the work of Epstein (2011), who identifies the major types of parental involvement that can be fostered by schools, and which have featured in the extensive literature on the subject:

(1) Parenting, defined as fulfilling the basic obligations of families to support health, safety, and conditions to promote child development (e.g., schools supporting parents in the development of parenting skills and understanding the home conditions necessary to foster child development).

(2) Communicating with families about school and their children's progress (e.g., parent-teacher conferences, report cards, and notices).

(3) Parent involvement at school (e.g., volunteering in the classroom, attending sports or other performances).

(4) Parent involvement in learning activities at home (e.g., supporting homework).

(5) Parent involvement in decision-making around education.

(6) Collaboration with community organizations (e.g., provision of after-school clubs or liaison with local businesses).

These six forms of involvement (Epstein 2011) form the framework for our analysis below. In addition to categorizing different forms of involvement, the literature has explored perspectives on responsibility for effective involvement. Western studies into parent and school views have explored the discourses that hold individual parents, 
rather than structural factors, as responsible for a child's performance (Goodall, 2021). However, perceptions of responsibility for parent involvement may differ between cultural contexts; views about the role of the family, the amount of trust placed in teachers, and the degree of centralization of an education system may all impact on whether, for example, students themselves, teachers, or centralized administrators are seen as responsible for promoting parental involvement (Al-Harrasi \& Al-Mahrooqi, 2014; Baker \& Hourani, 2014). A further concern in the international literature has been to explore barriers to parental involvement; both parental circumstances (such as work commitments) and parental attitudes may pose barriers to their involvement (Haack, 2007). Haack's study suggests that teachers and other parents may be more likely to blame less-educated parents for low involvement rather than viewing it because of their circumstances; in contrast, more-educated parents are more likely to be perceived as uninvolved because of their circumstances (Haack, 2007). The literature on this subject suggests perceived norms may play a key role in how involved parents become, regardless of their attitude to its importance (Bracke \& Corts, 2012).

The meaning attached to parental involvement by both parents and school personnel takes place within a sociocultural context; this has been demonstrated through an extensive literature exploring parental involvement amongst different minority communities within the United States (US) (e.g., Gonzalez et al., 2013). However, most research on parental views on involvement in schooling has been conducted in Western settings, and there has been little research on this topic in the Middle East (Moussa-Inaty \& De La Vega, 2013). The limited research available suggests that parents value parental involvement, but that their actual level of involvement does not always reflect these values. Al-Mahrooqi et al. (2016) surveyed nearly 400 Omani parents about involvement in their children's study of English at government school, however, the age of the children is not clear from their analysis. They found a mismatch between beliefs and reality - parents valued involvement and believed they should be involved, but in practice only had a limited involvement. Similarly, Al-Harrasi and Al-Mahrooqi (2014) surveyed 40 Omani parents' involvement in their children's schooling. Although most parents felt that their involvement was important, they reported little involvement in at-school activities. However, the reasons for low involvement that dominate the international literature - such as economic pressures on parents and the time constraints of large families - did not apply. Rather, it seemed that the parents had a large degree of trust in teachers, and therefore restricted their involvement to at-home activities. Further research has been conducted 
concerning the types of involvement in which parents participate. Inmeideh et al. (2018) used Epstein's model of different types of parental involvement to explore the perceptions of parents, teachers, school counsellors, and administrators in Qatar. They found that home learning received the highest score, while parent involvement in decision-making received the lowest. From the principals' perspective, Al-Taneiji (2013) studied school leaders' self-reported practices in involving parents in the UAE. They believed they used a variety of forms of communication to engage parents; however, Al-Taneiji notes that the types of engagement encouraged differ to those reported in Western studies (AI-Taneiji, 2013). The emphasis in the UAE was primarily on providing parents with information about student activities and student behavior. Research from Saudi Arabia (Alghazo \& Alghazo, 2015) into parental involvement in primary mathematics education found a positive correlation between parental involvement in home-based educational activities and children's mathematics attainment, but no correlation between mathematics attainment and parental involvement at school.

Other studies have explored the issue of who is seen as responsible for encouraging parental involvement (Al Harrasi \& Al-Mahrooqi, 2014; Baker \& Hourani, 2014). MoussaInaty and De La Vega (2013) found that the parents they surveyed in Abu Dhabi (in the UAE) viewed their involvement as important but thought that schools were responsible for encouraging and facilitating this. Baker and Hourani (2014) studied parent, teacher, and administrator views of parental involvement in seven Abu-Dhabi public-private primary schools (which use English as the medium of instruction). They found that while both parents and school valued parental involvement, there was a mismatch between their expectations about roles and responsibilities for fostering such involvement. For example, many parents felt unable to participate because of a lack of fluency in English, and they felt they had insufficient guidance from the school to enable them to offer meaningful curricular support. By contrast, administrators felt that parents did not have the skills to support learning and behavior at home. Each side saw the other as responsible for initiating parental involvement. Baker and Hourani (2014) argue that each side has unmet expectations for the other, which inhibit an effective partnership. Moreover, Al-Daihani (2005) explored supervisors' (schoolbased administrative staff responsible for communicating with families) attitudes toward family involvement in Kuwait middle schools. All six of Epstein's (2011) types of family involvement were viewed as important, although the supervisors placed less emphasis on parental involvement in decision-making and parental volunteering at school than on the other types of involvement. Responsibility for family involvement was seen as 
resting primarily with families themselves and administration, rather than with principals, teachers or students.

There remains a lack of research into the interaction between the cultural context of the Gulf and parental involvement. Al-Hassan (2020) stresses that educational reforms across the region have sought to avoid Westernization, instead placing an emphasis on promoting national identity and preserving traditions but argues that the barriers to parental involvement in the Gulf region are similar to those in the international literature. However, we suggest that the value placed on the extended family and cultural parenting practices means that parental involvement may look very different in the Gulf to how it is enacted in Western contexts. Al-Sumaiti's (2012) policy brief on parental involvement in Dubai notes features of the Emirati culture that can impact on academic attainment - in particular, the time that young children spend with maids and nannies from other countries - Al-Sumaiti proposes that policy-makers should take a number of steps to address such problems, including raising parental awareness of their role in education, and encouraging schools to take steps to foster parental engagement. Moreover, other research from the Gulf region suggests that the challenges of finding time for family involvement or meeting employment demands that have surfaced in Western literature do not always apply here (Al Harrasi \& Al-Mahrooqi, 2014).

Within the context of the cultures of the Gulf region, it is also important to pay attention to the role of gender in parental involvement. Bahrain is segregated based on gender throughout compulsory schooling in government schools, and a parent of one gender may not feel comfortable in a private conversation with a teacher of the opposite gender. A limited number of previous studies has started to explore the importance of the gender of both parent and child. Al-Taneiji (2008) conducted focus group discussions with Emirati secondary school students, finding that some students believed that their parents did not value girls' education, also noting that some mothers could not visit their sons' schools unaccompanied for cultural reasons. Midraj and Midraj (2011) studied the relationship between parental involvement and Grade 4 Arabic reading achievement in the UAE, finding that parents provided more learning resources at home for their daughters than for their sons. The available literature suggests that schools' approach to gender may also impact on parental involvement in schooling; in a study of a Saudi case-study school, Baydoun (2015) found that some fathers felt excluded by the gender-segregated school policies. Conversely, Al-Qaryouti and Kilani's (2015) study of the role of Omani parents in fostering emergent literacy skills by surveying 314 parents of kindergarten children found medium to high levels 
of involvement with no significant difference related to child's gender. Additionally, there was no difference between the involvement of mothers and fathers in their child's literacy development. However, Ridge and Jeon's (2020) large-scale study of paternal involvement in the Middle East, including 1684 participants from 10 countries, found that fathers are perceived as less involved than mothers, a differential that increases with paternal age.

The gender of educational professionals may also have an impact. In the investigation of Kuwaiti middle school principals summarized above, Al-Daihani (2005) found gender differences amongst principals in how they saw family involvement - for example, female principals were more likely to view the involvement of parents with limited education positively than were their male counterparts. In addition, female principals viewed their schools' communication with parents more positively than did male principals. Al-Daihani notes that in Kuwaiti culture of single-sex education, female teachers are more likely to communicate with mothers, although decisions regarding education are usually made by fathers, whereas male teachers generally communicate directly with fathers. In summary, then, there is a need for further research into parent involvement in this cultural context and although the current study did not examine gender specifically, future studies that focus on this aspect are important.

\subsection{Parental involvement in Bahraini schools}

Since 2005, Bahraini education has undergone major reform. Moreover, since 2008, the BQA has undertaken reviews of all Bahraini schools (Al-Hassan, 2020), which involve consultation with parents and evaluation of a school's relationship with its parent body. Nevertheless, there is very little research into parental involvement in children's education in Bahrain. In the only study currently available focusing on Bahrain, AlMahdi (2010b) studies parent and teacher views on involvement in learning of primary school mathematics through detailed study of a single classroom in a Bahraini rural village. He finds that the parents are primarily involved in Epstein's three categories of parenting, communicating, and supporting learning at home. The teacher participants in this study reported that parents demanded various actions from them but were not open to collaboration; meanwhile his parent participants did not feel that teachers encouraged them to maintain positive communication. Al-Mahdi (2010a) has shown that Bahraini parents differ in the cultural and social capital they bring to parent-teacher relationships in mathematics education. These studies have provided important insights 
into the views of Bahraini parents on their children's education; to date, however, wider aspects of parental involvement in Bahraini schools have lain beyond the scope of his research.

\section{Methodology}

The questionnaire used in this descriptive study was adapted from two doctoral theses: Al-Daihani (2005) who explored supervisors' attitudes toward family involvement in Kuwaiti middle schools and Fan (2012) who investigated parents' perceptions and practices in homework and their implications for school, teacher, and parent partnership in the US. The questionnaire was translated from English to Arabic, and two independent reviewers checked the translation. In addition, collecting demographic information, the survey explored views on the benefits of parental involvement; the school's role in supporting parental involvement; barriers to parental involvement; and different types of parental involvement activities. Although the number of parents surveyed is small, this is an unprecedented study of Bahraini parents' attitudes to education. Data were analyzed using the SPSS software to perform both the descriptive statistical analysis which includes frequencies, percentages, means and standard deviations, and ANOVA and $t$-tests to search for any possible significant differences among the participants. The Cronbach's alpha $(\alpha)$ to measure the internal consistency reliability of the questionnaire was 0.798 .

\subsection{Sample}

There are 112 public primary schools in Bahrain (57 boys' schools and 55 girls' schools); the data reported here are drawn from 16 of these schools, representing $14 \%$ of the total, an opportunistic sample gained by inviting school leaders attending a professional development course at Bahrain Teachers College to participate. The survey was distributed by them to a random sample of 20 parents from each school, who were invited to participate using a process of informed consent, with their anonymity guaranteed, with a total of 154 complete questionnaires being returned (48\%). A brief overview of the demographics of the sample is important before moving to the data analysis. Overall, $81.2 \%$ of the participants were mothers, with $13.6 \%$ being fathers, suggesting that mothers are perhaps more involved than fathers in their children's education. The remaining $5.2 \%$ were siblings of the primary school child. Around $82 \%$ of the sample were females and the data was collected from 4 boys' and 12 girls' schools. Participants 
were asked about the educational level of both parents in the family. Most of the fathers held secondary school certificates $(42.9 \%)$ or undergraduate degrees $(45.5 \%)$, with small numbers having either higher or lower levels of qualification. Similarly, the mothers mainly held either secondary school certificates $(32.5 \%)$ or undergraduate degrees (55.8\%). This indicates that most of the parents who participated in the study have completed school or university-level education, which reflects the nature of the Bahraini society. Most of the families who participated in this study come from average or good socioeconomic backgrounds, according to their school principals; unfortunately, precise demographic data on the individual schools is not available. The illiteracy level in Bahrain is low (2.4\%) in comparison to other countries in the region (Al-Watan Newspaper Online, September 8, 2019). The net enrolment rate in secondary education was $89.1 \%$ in 2019 - 94\% for females and $84.8 \%$ for males (UNESCO, 2021). However, Bahraini national statistics indicate that female workers constitute $39 \%$ of the general national workforce in the country and the percentage of female workers in the public sector is $50 \%$ (Al-Watan Newspaper Online, November 30, 2018); some families have dual earners, while in others, the mother is not employed. Divorce is common; in 2019 there were 6039 marriage registrations and 1929 divorces (Al-Ayam Newspaper Online, May 26, 2020).

\section{Findings}

Table 1 shows parents' views of the average grades their child receives in school. Majority of the parents (72.1\%) indicated that their child's grades are excellent, with a few (18.2\%) indicating they are very good. In other words, the parents surveyed had a high level of satisfaction with their child's current academic performance, although it is unclear whether this is because parents of high achievers were more likely to respond to the survey or because there are generally high levels of achievement at the primary level. From the researchers' experience, high achievement seems to be common among primary school children due to a focus on formative and collaborative assessment at that age.

Table 2 shows the results of the survey questions related to parents' general experiences about their involvement in children's learning. It was evident that the participants believed that parental involvement was beneficial to children. Most of the participants (92.9\%) highly agreed or agreed that parents should be involved in their child's school. Similarly, most of the participants (96.1\%) highly agreed or agreed that parental involvement improves primary school students' academic success. However, most participants 


\section{Table 1}

Student achievement level reported by parents

Student achievement level
Excellent
Very good
Good
Average
Total

\begin{tabular}{|c|}
\hline Frequency \\
111 \\
28 \\
14 \\
1 \\
154 \\
\hline
\end{tabular}

\begin{tabular}{|c|}
\hline Percentage \\
72.1 \\
18.2 \\
9.1 \\
0.6 \\
100.0 \\
\hline
\end{tabular}

(87\%) felt that it was not necessary for parents with limited education to be involved, suggesting that they conceptualize parental involvement as mainly linked to direct academic support. They also expressed a concern that involved parents can undermine the performance and effectiveness of schools, with $94.2 \%$ agreeing or strongly agreeing that this was possible. Parents seemed to be concerned whether their involvement in their children's schooling might be misinterpreted as undermining the authority of school. However, parents were generally happy about the level of communication offered by the school and thought that they should be involved in their child's school. The participants expressed high levels of satisfaction with the current efforts made by their child's school to foster parental involvement. For example, 92.9\% agreed or strongly agreed that the school took consistent measures to support parental involvement.

In terms of Epstein's (2011) forms of parental involvement, large numbers of parents agreed or strongly agreed that the school addressed each of these - parenting (92.9\%), communicating (95.5\%), learning at home (89\%), volunteering (81.7\%), and collaboration with the community (83.2\%). This indicates that the participating parents saw their role mainly as providing a suitable home environment and focusing on children's learning at home. They also prefer to have good and continuous communication with the school. However, there is less agreement about their role as volunteers or involvement in the decision-making process.

Table 3 shows the importance participants ascribed to each type of involvement during their child's primary school years. The different activities were ranked by adding the percentage of parents who rated each as either very important or important: encouraging children to learn in everyday life settings (100\%); providing a home environment that supports learning (98\%); regular communication with teachers and administrators (98\%); assisting students at home by doing such things as encouraging them to do homework, and helping them to schedule out-of-school time wisely (93.8\%); volunteering at the school (83.8\%); and being involved in school decision-making and/or parent 
Table 2

General parental views towards parental involvement

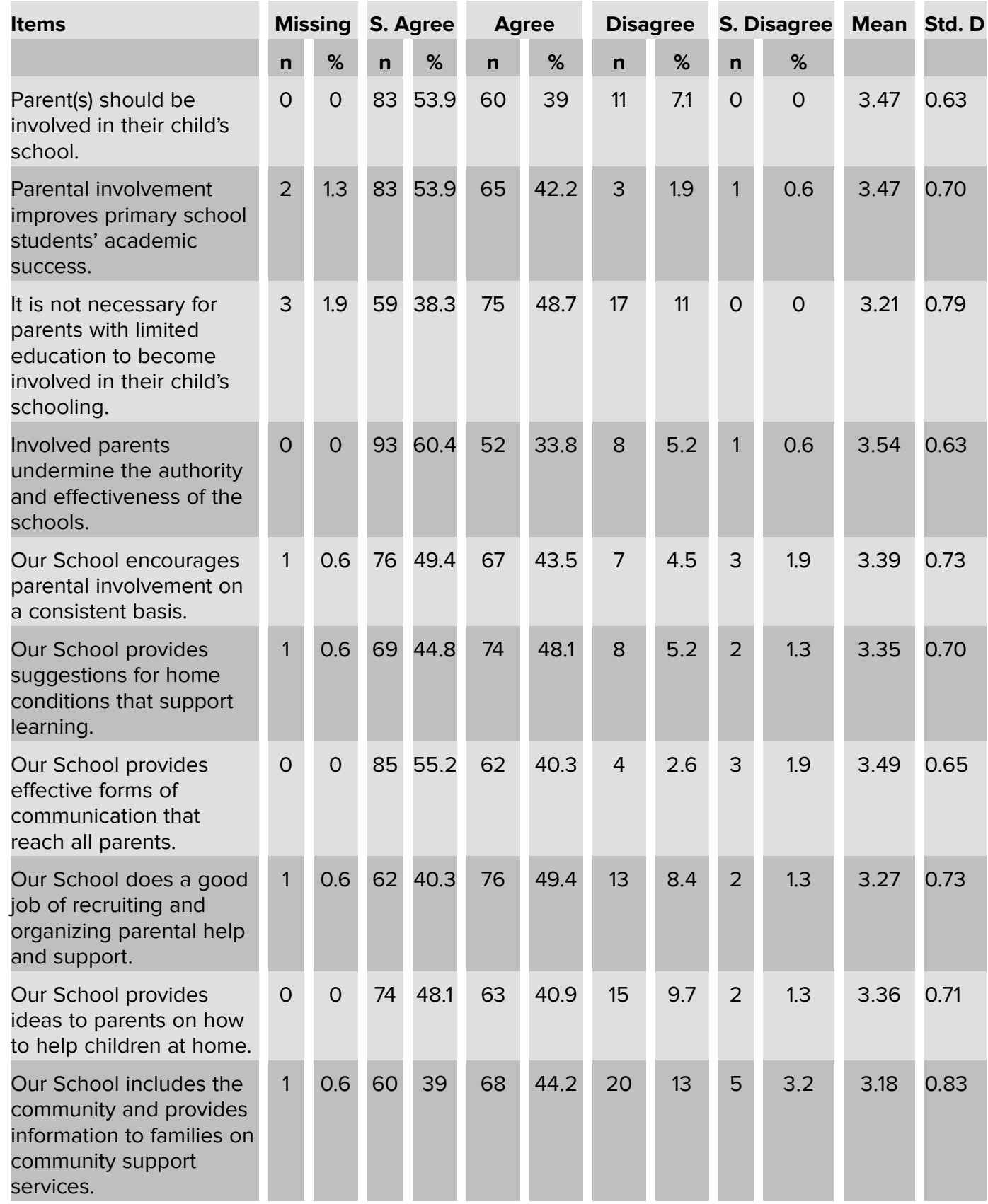

organizations (82.3\%). The high value that these Bahraini parents placed on parental involvement echoes the views of parents previously researched in the Gulf region (AlMahrooqi et al. 2016; Al-Harrasi \& Al-Mahrooqi, 2014); however, it is in contrast to these earlier studies that Bahraini parents report being currently satisfied with high levels of involvement being facilitated by schools. 
Table 3

Parent views on the importance of each type of involvement (family's role)

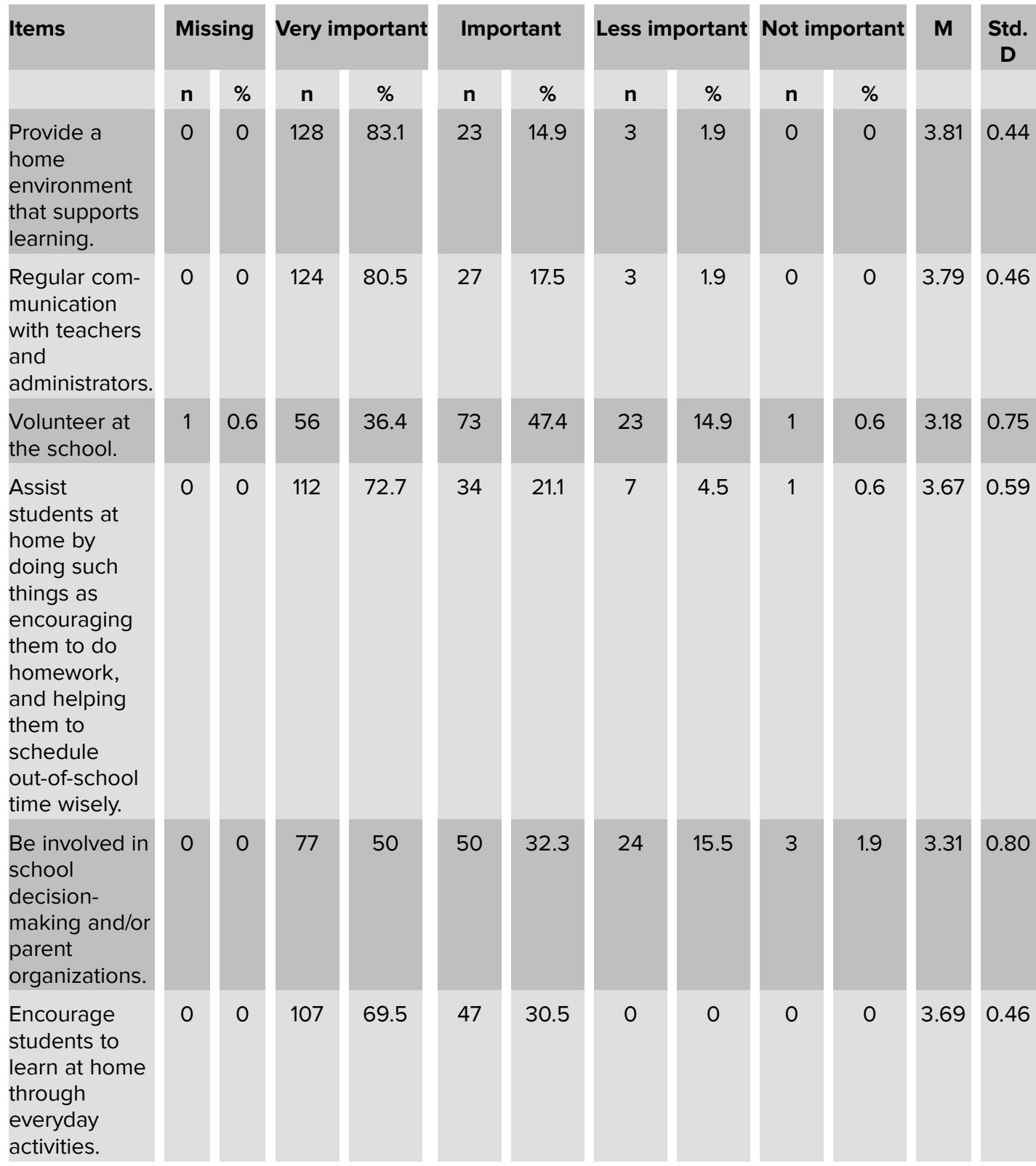

Table 4 shows the results of the survey's questions related to parents' views on who is responsible for initiating family involvement in the school. It is evident from this table that participants felt that most responsibility lay with the school administration, the social work supervisors, and teachers, in order of importance. Parents are given less responsibility than either of these groups, and students least of all. However, responsibility is still given to parents as well. These findings echo the studies by Mousaa-Inaty and De La Vega (2013) and Baker and Hourani (2014) in the UAE, which 
Table 4

Parent views on who is responsible for initiating family involvement

\begin{tabular}{|c|c|c|c|c|c|c|c|c|c|c|c|c|}
\hline \multirow[t]{2}{*}{ Items } & \multicolumn{2}{|c|}{ Missing } & \multicolumn{2}{|c|}{$\begin{array}{l}\text { Strongly } \\
\text { responsible }\end{array}$} & \multicolumn{2}{|c|}{ Responsible } & \multicolumn{2}{|c|}{$\begin{array}{l}\text { Less } \\
\text { responsible }\end{array}$} & \multicolumn{2}{|c|}{$\begin{array}{l}\text { Not responsi- } \\
\text { ble }\end{array}$} & \multirow[t]{2}{*}{ M } & \multirow[t]{2}{*}{$\begin{array}{c}\text { Std. } \\
\text { D }\end{array}$} \\
\hline & $\mathbf{n}$ & $\%$ & $\mathbf{n}$ & $\%$ & $\mathbf{n}$ & $\%$ & $\mathbf{n}$ & $\%$ & $\mathbf{n}$ & $\%$ & & \\
\hline $\begin{array}{l}\text { Administrators } \\
\text { (school leadership) }\end{array}$ & 1 & 0.6 & 121 & 78.6 & 25 & 16.2 & 7 & 4.5 & 0 & 0 & 3.72 & 0.61 \\
\hline $\begin{array}{l}\text { Supervisors } \\
\text { (school-based } \\
\text { social workers with } \\
\text { administrative } \\
\text { responsibilities) }\end{array}$ & 1 & 0.6 & 101 & 65.6 & 41 & 26.6 & 9 & 5.8 & 1 & 0.6 & 3.76 & 2.47 \\
\hline Families & 1 & 0.6 & 69 & 44.8 & 64 & 41.6 & 16 & 10.4 & 4 & 2.6 & 3.77 & 0.80 \\
\hline Teachers & 1 & 0.6 & 93 & 60.4 & 43 & 27.9 & 15 & 9.7 & 2 & 1.3 & 3.46 & 0.78 \\
\hline Students & 1 & 0.6 & 58 & 37.7 & 49 & 31.8 & 30 & 19.5 & 16 & 10.4 & 2.95 & 1.02 \\
\hline
\end{tabular}

both found that parents placed more responsibility upon educational professionals than upon families for getting parents involved in schools.

Table 5 shows the results of the survey questions related to parents' identification of the importance of each barrier to family involvement in their child's education. Parents' responsibilities were seen by $97.9 \%$ of participants as very important or important barriers to their involvement. Other factors seen as important or very important barriers to parental involvement were administrators' relationships with teachers and/or parents (97.4\%); teachers' responsibilities (94.2\%); different personalities of the teachers (81.2\%); and students becoming independent and not wanting parent involvement (74.8\%). In contrast to Haack's (2007) study from the US, then, parents saw parents' and teachers' circumstances as more important barriers than characteristics of the teachers or parents themselves.

Table 6 shows the results of the survey's questions related to parents' views on the importance of each type of involvement from the school's role perspective. Most of the parents $(99.4 \%)$ thought that it is very important or important that the school should design effective forms of communication to reach all parents. They also thought that it is highly important or important (98.9\%) that the school should offer ideas to them on how to help children at home. However, slightly fewer parents (87.7\%) thought that it is very important or important that school should recruit and organize parent help and support at the school. Similarly, the majority of parents $(90.7 \%)$ thought that it is very important or important that school should provide them and others in the community with opportunities to participate in school decision-making; the relatively 
Table 5

Parent views on importance of each barrier to family involvement

\begin{tabular}{|c|c|c|c|c|c|c|c|c|c|c|c|c|}
\hline \multirow[t]{2}{*}{ Items } & \multicolumn{2}{|c|}{ Missing } & \multicolumn{2}{|c|}{ Very important } & \multicolumn{2}{|c|}{ Important } & \multicolumn{2}{|c|}{ Less important } & \multicolumn{2}{|c|}{ Not important } & \multirow[t]{2}{*}{$\mathbf{M}$} & \multirow{2}{*}{$\begin{array}{c}\text { Std. } \\
\text { D }\end{array}$} \\
\hline & $\mathbf{n}$ & $\%$ & $\mathbf{n}$ & $\%$ & $\mathbf{n}$ & $\%$ & $\mathbf{n}$ & $\%$ & $\mathbf{n}$ & $\%$ & & \\
\hline $\begin{array}{l}\text { Parents' } \\
\text { responsibilities }\end{array}$ & 0 & 0 & 120 & 77.9 & 31 & 20 & 2 & 1.3 & 0 & 0 & 3.75 & 0.45 \\
\hline $\begin{array}{l}\text { Teachers' } \\
\text { responsibilities }\end{array}$ & 1 & 0.6 & 113 & 73.4 & 32 & 20.8 & 8 & 5.2 & 0 & 0 & 3.66 & 0.64 \\
\hline $\begin{array}{l}\text { Administrators' } \\
\text { relationships with } \\
\text { teachers and/or } \\
\text { parents }\end{array}$ & 0 & 0 & 103 & 66.9 & 47 & 30.5 & 4 & 2.6 & 0 & 0 & 3.64 & 0.53 \\
\hline $\begin{array}{l}\text { Students } \\
\text { become } \\
\text { independent and } \\
\text { do not want } \\
\text { parent } \\
\text { involvement }\end{array}$ & 4 & 2.6 & 49 & 31.6 & 67 & 43.2 & 33 & 21.3 & 1 & 0.6 & 3.01 & 0.89 \\
\hline $\begin{array}{l}\text { Different } \\
\text { personalities of } \\
\text { the teachers }\end{array}$ & 4 & 2.6 & 63 & 40.9 & 62 & 40.3 & 19 & 12.3 & 6 & 3.9 & 3.13 & 0.95 \\
\hline
\end{tabular}

lower emphasis placed on parental involvement in decision-making echoes the work of Ihmeideh et al. (2018).

In further analysis of the data, one-way ANOVA was used to determine whether there are any statistically significant differences between the means of different groups of parents according to the following variables: relationship to child, child's school year, student achievement level, father's education level, and mother's education level. The findings show that there were no significant differences between the means of the subgroups (fathers, mothers, sisters, and brothers) on most questionnaire sub-scales. The main results that emerged from this analysis are that different types of family members shared similar views on the first three subscales of the questionnaire: general views on family-school relations, type of family involvement, and responsibility for initiating family involvement. In further analysis, a $t$-test was used to find any statistically significant differences between the means of male relations to child and female relations to child. The $t$-test results indicate that there were no significant differences between the two groups on most of the questionnaire items except the following: Q12 social work supervisors are responsible for initiating family involvement in the school ( $t=$ $2.146 p=0.033$, i.e., $<0.05$ ), and Q21 schools should focus on establishing appropriate connections with the community that will enhance and assist the school ( $t=-2.416 p$ 
Table 6

Parent views on the importance of each type of involvement (school's role)

Items
Providing information
to families on how to
establish home
environments that
support learning.
Designing effective
forms of
communication to
reach all parents.
Recruiting and
organizing parent
help and support at
the school.
Providing ideas to
parents on how to
help children at
home.

Providing parents and others in the community with opportunities to participate in school decision-making.

Establishing appropriate connections with the community that will enhance and assist the school.

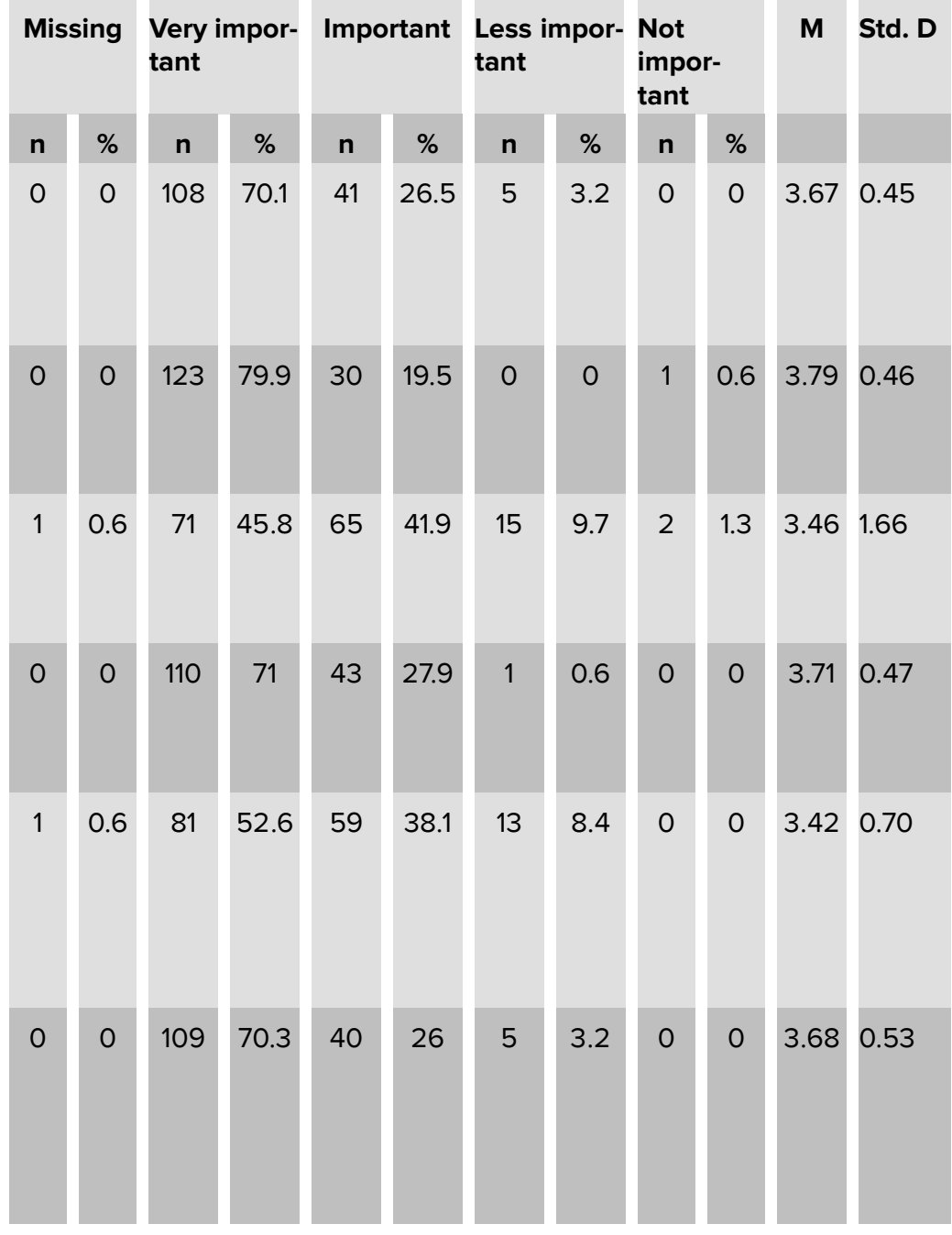

$=0.033$, i.e., $<0.05)$. This indicates that male and female participants tend to share similar views regarding the items of the subscale.

\section{Discussion}

This exploratory study provides preliminary data on how Bahraini parents view parental involvement in schools. Following the work of other researchers into parental attitudes in the Gulf (e.g., Al-Harrasi \& Al-Mahrooqi, 2014), we found that our participants in Bahrain considered parental involvement to be important. Indeed, the most striking feature of the data is the extremely high importance that parents placed upon every form of participation identified by Epstein (2011). Whilst some of Epstein's categories received a higher importance than others, the majority of parents saw every form of involvement 
as important. However, they also identified a range of barriers as preventing effective parental involvement, seeing parental responsibilities as the most important.

The quantitative data presented here also offer insight into the nature of homeschool relations in the Bahraini context; we suggest that Bahraini parents' views can be characterized overall as a school-centered approach of home-school relations. In this approach, parents think that schools are responsible for taking the first step in initiating involvement activities with them. This echoes the work of other researchers in the Gulf such as Moussa-Inaty and De La Vega (2013). Most of the parents preferred to be engaged in parenting activities and helping their children to learn at home and did not show as high an interest in taking the role of volunteering in school or engaging in decision-making responsibilities, although interest here was still quite high. In addition, more emphasis was placed upon school administrators in being highly responsible for parental involvement than upon parents themselves. Further research is needed to ascertain why parents place less emphasis on their own initiative - for example, whether it is a result of other time pressures and responsibilities, or whether school procedures or programs place more emphasis on the role of schools themselves.

Although our data do not enable us to explore the role of cultural factors, such as attitudes to gender, in any detail, it should be noted that most respondents were mothers and the majority of schools that participated were girls' schools; indeed, the very small number of males and boys' schools who participated in the study prevented statistically significant comparisons by gender. This could potentially build on Ridge and Jeon's (2020) study suggesting that fathers are less involved than mothers across the Gulf states. Interestingly, our data suggest that there is no gender differential on the first three subscales of the questionnaire: general views on family-school relations, type of family involvement, and responsibility for initiating family involvement. Some significant differences existed related to barriers to family involvement and the importance for each type of involvement which we were unable to attribute to specific groups due to the variation in subgroup sizes. Again, this suggests an important area for further research; using a qualitative approach might help to elicit any differences between mother and fathers related to cultural or social factors that can influence the nature of their involvement. In addition, further cultural differences in how parental involvement is enacted could be explored through qualitative means.

It is important to acknowledge some of the limitations of this exploratory study. For example, whilst the data show that there was a high similarity among the participants in terms of their positive attitudes toward school and their good relations and involvement 
in their children's schooling and education, one possible explanation for this is that the participants generally share similar characteristics (e.g., the educational level of the parents is generally high and their children are also generally high achievers); hence, these findings might not be generalizable to parents lacking these characteristics who may be less likely to participate in such research studies. In addition, the dataset reported on here does not include other parental demographic factors, such as socioeconomic background, which may also play an important role. Moreover, our data focus exclusively on the parents of primary school children, and further studies are needed to understand home-school relations after primary level in Bahrain. Future studies should also focus on studying contrasting groups of parents (e.g., parents of high achievers and low achieving students, parents from varied academic or socioeconomic levels). Also, by virtue of their participation in the research, participants were already more involved than others. It would be useful in future studies to find ways to reach parents who are less involved.

\section{Conclusion}

This quantitative study of parents of primary school students in Bahrain suggests that Bahraini parents place a high emphasis on all forms of parental involvement (Epstein, 2011) and have a high satisfaction with current opportunities for parental participation offered by their schools. They espouse a school-centered view of homeschool relations, with most emphasis placed upon school administrators' role in ensuring parental participation, although there is nevertheless an important emphasis given to the responsibility of parents themselves. The study was largely completed by mothers, possibly suggesting that fathers are less directly involved in school-related matters (Ridge \& Jeon, 2020), however, this does not mean that they are not involved in supporting their children's education at home. This study has identified several areas for further research into Bahraini parents' views of parental involvement, noting important limitations of the current study; it has been stressed that this is an initial, exploratory study, responding to the research gap in the Bahraini context.

Policy recommendations from this exploratory study are therefore tentative, pending further research. However, these exploratory findings suggest increased provision of preservice and in-service teacher training in the area of supporting positive homeschool communication, allowing schools to exchange their experiences in building strong home-school relations, and overcoming barriers to parental involvement. In addition, the study underscores parental commitment to diverse forms of involvement, 
thereby supporting schools' inclusion of parents in volunteering and decision-making, and a family centered approach to their education. Most importantly, this study points to the fecundity of research into parental involvement in Bahrain and the wider GCC region, with studies that explore the specific cultural, social, and educational contexts of the region being of necessity.

\section{Acknowledgements}

None.

\section{Funding Information}

No funding source have been involved at any stage of the research.

\section{Competing Interests}

The authors have no competing interests to declare.

\section{Author Biographies}

Osama Al-Mahdi is an assistant professor in Bahrain Teachers College, University of Bahrain. He completed his PhD from University of Bristol, UK. He is a fellow of the Advance Higher Education in the UK. His research interests include teachers' professional development, inclusive education in primary education, educational leadership, and home-school relationships.

Lucy Bailey is an associate professor and Head of Education Studies at the Bahrain Teachers College, Zallaq, Bahrain. She has written extensively about international education, including international schooling, the internationalization of higher education, and refugee education. Her research interests also include educational leadership and discourses of parenting.

\section{References}

[1] Al-Daihani, S. (2005). Supervisors' attitudes toward family involvement in Kuwait middle schools [Unpublished doctoral dissertation]. Blacksburg, Virginia: Virginia 
Polytechnic and State University.

[2] Alghazo, Y., \& Alghazo, R. (2015). The effect of parental involvement and socioeconomic status on elementary students' mathematics achievement. Journal of Social Sciences and Humanities, 1(5), 521-527.

[3] Al-Ayam Newspaper Online. (2020, May 26). تراجع زواج البحرينين وارتفاع [The decline of Bahraini marriages and the rise of divorce]. https://www.alayam.com/alayam/first/858321/News.html

[4] Al-Hassan, S. (2020). Parental involvement in education in the Gulf region. In: J. E. Lansford, A. B. Brik, \& A. M. Badahdah, Families and social change in the Gulf region (pp. 80-95). London: Routledge.

[5] Al-Mahdi, O. (2010a). Linking home and school mathematics: A qualitative case study in a Bahraini Primary School. Germany: LAP Lambert Academic Publishing.

[6] Al-Mahdi, O. (2010b). A qualitative investigation of home-school relationships and children's mathematics learning in-and out-of-school in Bahrain. Procedia - Social and Behavioral Sciences, 8, 427-438. https://doi.org/10.1016/j.sbspro.2010.12.059

[7] Al-Mahrooqi, R., Denman, C., \& Al-Maamari, F. (2016). Omani parents' involvement in their children's English education. SAGE Open 6(1), 1-12.

[8] Al-Harrasi, S., \& Al-Mahrooqi, R. (2014). Investigating Omani parents' involvement in their children's schooling. European Journal of Scientific Research, 117(2), 272-286.

[9] Al-Qaryouti, I. \& Kilani, H. (2015). Role of Omani parents: Fostering emergent literacy skills. International Journal of Primary, Elementary and Early Years Education, 43(3), 336-348.

[10] Al-Sumaiti, R. (2012). Parental involvement in the education of their children in Dubai (Policy brief 30). Retrieved from https://khda.gov.ae/CMS/WebParts/TextEditor/ Documents/Parental_Involvement_in_the_Education.pdf

[11] Al-Taneiji, S. (2008). Students' perceptions of parental involvement in United Arab Emirates Secondary Schools. Journal of Educational \& Psychological Sciences, 9(02), 11-29.

[12] Al-Taneiji, S. (2013). The role of leadership in engaging parents in United Arab Emirate schools. International Education Studies, 6(1), 153-165.

[13] Al-Watan Newspaper Online. (2020, September 8). وزير التربية: بو نسبة الأمية في البحرين [Ministry of Education: 2\% of the illiteracy rate in Bahrain is among the lowest in the world]. https://www.alayam.com/online/local/871209/News.html

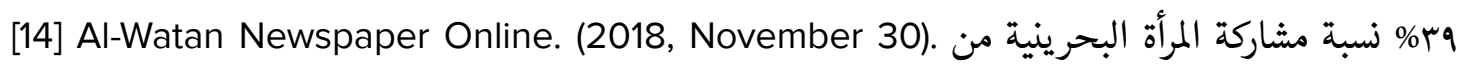
39\% of the Bahraini women’s participation rate in the total national workforce in Bahrain]. 
[15] Baker, F. S., \& Hourani, R. B. (2014). The nature of parental involvement in the city of Abu Dhabi in a context of change. Education, Business and Society: Contemporary Middle Eastern Issues, 7(4), 186-200.

[16] Baydoun, N. (2015). The perceived effect of parental participation on the academic achievement of female English as a second language Middle School Students in the Persian Gulf region. Marriage \& Family Review, 51(1), 22-38.

[17] Bracke, D., \& Corts, D. (2012). Parental involvement and the theory of planned behavior. Education, 133(1), 188-201.

[18] Daniel, G. (2011). Family-school partnerships: Towards sustainable pedagogical practice. Asia-Pacific Journal of Teacher Education, 39(2), 165-176.

[19] Desforges, C. \& Abouchaar, A. (2003). The impact of parental involvement, parental support and family education on pupil achievements and adjustment: A literature review. United Kingdom: Queen's Printer.

[20] Education and Training Quality Assurance Authority. (2015). Schools reviews handbook. http://www.bqa.gov.bh

[21] Epstein, J. L. (2011). School, family, and community partnerships: Preparing educators and improving schools (2nd ed.). Boulder, CO: Westview.

[22] Fan, Q. (2012). Parents' perceptions and practices in homework: Implications for school, teacher and parent partnerships [Unpublished doctoral dissertation]. USA: University of Illinois at Chicago.

[23] Gonzalez, L. M., Borders, L. D., Hines, E. M., Villalba, J. A., \& Henderson, A. (2013). Parental involvement in children's education: Considerations for school counselors working with Latino immigrant families. Professional School Counseling, 16(3), 185192.

[24] Goodall, J., \& Montgomery, C. (2014). Parental involvement to parental engagement: A continuum. Educational Review, 66(4), 399-410.

[25] Goodall, J. (2021). Parental engagement and deficit discourses: Absolving the system and solving parents. Educational Review, 73(1), 98-110.

[26] Haack, M. (2007). Parents' and teachers' beliefs about parental involvement in schooling [Unpublished doctoral dissertation]. The Graduate College at the University of Nebraska.

[27] Ihmeideh, F., AlFlasi, M., Al-Maadadi, F., Coughlin, C., \& Al-Thani, T. (2018). Perspectives of family-school relationships in Qatar based on Epstein's model of six types of parent involvement. Early Years, 4O(2), 188-204.

[28] Goodall, J. \& Montgomery, C. (2014). Parental involvement to parental engagement: A continuum. Educational Review, 66(4), 399-410. 
[29] Karolak, M. (2010). Preserving Arab culture in the Kingdom of Bahrain. In I. C. Veljanova, (Ed.), Perception, Meaning and Identity (pp. 23-34). The Netherlands: Brill.

[30] LaRocque, M., Kleiman, I., \& Darling, S. M. (2011). Parental involvement: The missing link in school achievement. Preventing School Failure, 55(3), 115-122.

[31] Midraj, S., \& Midraj, J. (2011). Parental involvement and grade four students' Arabic reading achievement. European Journal of Educational Studies, 3(2), 245-260.

[32] Moussa-Inaty, J., \& De La Vega, E. (2013). From their perspective: Parental involvement in the UAE. International Journal of Sociology of Education, 2(3), 292312.

[33] Ridge, N., \& Jeon, S. (2020). Father involvement and education in the Middle East: Geography, gender, and generations. Comparative Education Review, 64(4), 725748.

[34] UNESCO. (2021). Bahrain. Retrieved from http://uis.unesco.org/en/country/bh 